\title{
O ENSINO DE EQUILÍBRIO QUÍMICO A PARTIR DAS ETAPAS DA SITUAÇÃO DE ESTUDO: UM RELATO DE CASO VIVENCIADO POR LICENCIANDOS EM FORMAÇÃO
}

\section{A PROPOSITION FOR THE TEACHING OF CHEMICAL EQUILIBRIUM FROM THE STAGES OF A STUDY SITUATION: A CASE REPORT EXPERIENCED BY UNDERGRADUATE STUDENTS IN TRAINING}

\author{
Evandro Bonifácio ${ }^{1}$ \\ Ana Beatriz da Silva ${ }^{2}$ \\ Ana Paula Hilário Gregório ${ }^{3}$ \\ Enio de Lorena Stanzani ${ }^{4}$
}

\begin{abstract}
Resumo: O presente artigo tem como objetivo analisar o desenvolvimento de uma Situação de Estudo (SE) para o ensino de Equilíbrio Químico, evidenciando as potencialidades dessa proposta para os processos de ensino e de aprendizagem na Educação Básica. A SE foi elaborada por dois licenciandos de um curso de Licenciatura em Química e desenvolvida em um colégio da rede pública com a participação de aproximadamente 30 estudantes do $2^{\circ}$ ano do Ensino Médio. Dentre as atividades propostas na SE, os estudantes responderam questões relacionadas à situação em estudo, as quais foram coletadas para posterior análise, de acordo com os pressupostos da Análise de Conteúdo. Como resultado, destacamos o envolvimento dos estudantes nas atividades propostas, sendo possível constatar a reelaboração conceitual nas respostas dadas ao longo das aulas, embora alguns estudantes ainda apresentem dificuldades relacionadas à explicação e compreensão dos fenômenos químicos estudados com relação ao nível submicroscópico.
\end{abstract}

Palavras-chave: Estágio Supervisionado; Situação de Estudo; Equilíbrio Químico.

\begin{abstract}
This study aims to analyze the development of a Study Situation (SS) for the teaching of Chemical Equilibrium, highlighting the potentiality of this proposition for teaching and learning processes in Basic Education. The SS was elaborated by two undergraduate Chemistry students and developed in a state school with the participation of approximately 30 students in their second year of High School. Among the activities proposed in the SS, students answered questions related to the situation under study. These answers were collected for further analysis, according to the assumptions of Content Analysis. As a result, we draw attention to students' involvement in the activities. Although some students still presented difficulties related to the explanation and understanding of the chemical phenomena studied in the submicroscopic level, it was possible to verify the conceptual re-elaboration in the answers given during the classes.
\end{abstract}

\footnotetext{
${ }^{1}$ Licenciado em Química pela Universidade Tecnológica Federal do Paraná (UTFPR). Mestrando em Engenharia Ambiental pela UTFPR, Apucarana, Paraná, Brasil. E-mail: bonifacioevandro@gmail.com

${ }^{2}$ Licenciada em Química pela Universidade Tecnológica Federal do Paraná (UTFPR). Mestrando em Engenharia Ambiental pela UTFPR, Apucarana, Paraná, Brasil. E-mail: abeatrizsilva1994@ hotmail.com ${ }^{3}$ Doutora em Ensino de Ciências e Educação Matemática pela Universidade Estadual de Londrina (UEL), Londrina, Paraná, Brasil. E-mail: anaph_ag@ @otmail.com

${ }^{4}$ Doutor em Educação para a Ciência pela Universidade Estadual Paulista Júlio de Mesquita Filho (UNESP). Professor Adjunto na Universidade Tecnológica Federal do Paraná, Apucarana, Paraná, Brasil. E-mail: eniostanzani@utfpr.edu.br
} 
DOI: http://dx.doi.org/10.33238/ReBECEM.2020.v.4.n.1.23721

Keywords: Supervised Internship; Study Situation; Chemical Equilibrium.

\section{Introdução}

Ao longo dos últimos anos diversas pesquisas na área de Ensino de Ciências têm indicado estratégias e metodologias de ensino com o objetivo de tornar os processos de ensino e de aprendizagem na Educação Básica mais significativos e condizentes com a realidade dos estudantes. As Situações de Estudo (MALDANER et al., 2001; MALDANER, 2007), os Três Momentos Pedagógicos ${ }^{5}$ (DELIZOICOV; ANGOTTI; PERNAMBUCO, 2009), os Estudos de Caso (SÁ; QUEIROZ, 2009), o Ensino por Investigação (CARVALHO, 2013), as abordagens com ênfase CTSA (SANTOS; AULER, 2013), dentre outras propostas, buscam, por meio da problematização dos conhecimentos relacionados à vivência dos estudantes e da utilização de diferentes recursos de ensino, propiciar que os estudantes se tornem sujeitos ativos na construção do conhecimento.

Nessa perspectiva, na Situação de Estudo (SE), proposta por Maldaner et al. (2001) e fundamentada na teoria sócio-histórico-cultural de Vigotski, por meio da problematização dos conhecimentos prévios e da utilização de diferentes estratégias de ensino, considera-se que "as vivências e as relações que o aluno estabelece com seu meio são importantes na construção do conhecimento que possibilita a formação das funções psicológicas superiores, como a capacidade de generalizar e de abstrair" (SANGIOGO et al., 2013, p. 38). É preciso atentar também que, no contexto da SE, entende-se que o conhecimento não é construído espontaneamente, “mas em processos intersubjetivos relacionados aos enfrentamentos de problemas comuns, o que remete para a necessidade de o professor introduzir conhecimentos específicos" (SANGIOGO et al., 2013, p. 41).

Vale ressaltar ainda outro aspecto importante na fundamentação da SE, o qual diz respeito à compreensão de que "o conhecimento e o entendimento acerca do que é produzido pelo homem são construídos quando indivíduos se engajam socialmente em conversações e atividades sobre problemas e tarefas comuns" (MALDANER, 2007, p. 111) - compreensão que, de acordo com o autor, está em sintonia com os pressupostos defendidos por Vigotski.

\footnotetext{
${ }^{5}$ Sugestão de leitura complementar: GEHLEN, S. T.; MALDANER, O. A.; DELIZOICOV, D. Momentos pedagógicos e as etapas da situação de estudo: complementaridades e contribuições para a Educação em Ciências. Ciência \& Educação, v. 18, n. 1, 2012.
} 


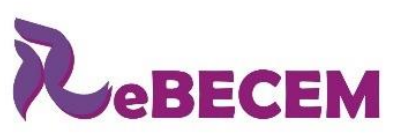

Revista Brasileira de Educação em

Ciências e Educação Matemática

DOI: http://dx.doi.org/10.33238/ReBECEM.2020.v.4.n.1.23721

Assim, ao incluir situações reais no contexto de sala de aula, as quais os alunos conhecem e para as quais possuem ideias anteriores, estabelece-se um movimento de interação dos estudantes com os conceitos científicos e com o professor e cria-se um ambiente facilitador para a aprendizagem, objetivando um importante aspecto defendido na SE: a permanente significação conceitual (STANZANI, 2018; SANGIOGO et al., 2013; MALDANER et al., 2001).

Para o desenvolvimento da SE em sala de aula são propostas três etapas. A primeira delas, Problematização, busca, a partir da proposição de um problema vinculado à uma situação de vivência dos estudantes, levantar o conhecimento prévio sobre o conteúdo que irá ser abordado. O importante nessa etapa é que os estudantes tenham o primeiro contato com a palavra/conceito, a fim de que as concepções espontâneas possam ser ressignificadas ao longo da SE (AUTH et al., 2004).

$\mathrm{Na}$ segunda etapa, Primeira Elaboração, são propostas atividades para o aprofundamento dos conceitos trabalhados, com o objetivo de extrapolar o contexto inicial, possibilitando ao estudante o contato com o conceito científico em novas situações. Na última etapa, Função da Elaboração e Compreensão Conceitual, volta-se ao problema inicial, a fim de evidenciar a evolução conceitual. Nessa etapa também são propostas novas situações, nas quais os estudantes devem solucionar os problemas utilizando os conceitos reelaborados ao longo da SE (GEHLEN; MALDANER; DELIZOICOV, 2012).

Outro aspecto importante na fundamentação da SE refere-se ao entendimento de Ciência defendido pelos autores. Segundo Maldaner et al., (2001), na SE, a Ciência:

[...] é significada como uma criação cultural/histórica específica, como um conhecimento estruturado que, simplificando a complexidade do real, tem grande potencialidade de ser inserida como uma compreensão relevante sobre "algo" no mundo, coparticipando no cumprimento da função fundamental e insubstituível da escola, na apropriação de linguagens e pensamentos específicos capazes de uma nova ação no meio (MALDANER et al., 2001, p. 116).

Complementando, Auth et al., (2004, p. 255) afirma que, na SE, "não é aceita a ideia de Ciência cristalizada, imutável e produtora de verdades às quais não cabem questionamentos [...], pois quem produz Ciência dificilmente admite verdades definitivas". Enfatiza-se, assim, a importância em contemplar os conhecimentos quanto à sua especificidade e aos aspectos históricos de sua elaboração, evitando-se a propagação de "visões vinculadas ao processo de produção do conhecimento científico que sejam, por exemplo: empírico-indutivista e ateórica, rígida/acabada, a-problemática, a-histórica, 
DOI: http://dx.doi.org/10.33238/ReBECEM.2020.v.4.n.1.23721

exclusivamente analítica, individualista, descontextualizada e socialmente neutra" (SANGIOGO et al., 2013, p. 51).

Desse modo, a partir da abordagem proposta na SE, buscou-se melhorar a compreensão dos conceitos científicos relacionados ao conteúdo de Equilíbrio Químico, no qual os estudantes apresentam grande dificuldade de aprendizagem. Santos, Andrade e Izaias (2016) apontam "a abstração dos conceitos da Química, em particular do conteúdo de Equilíbrio Químico como uma das razões que dificultam a compreensão e apropriação dos conceitos" (s/p). Além disso, por muitos pesquisadores e professores da Educação Básica este é considerado um conteúdo problemático para o ensino e aprendizagem (MASKILL; CACHAPUZ, 1989, apud MACHADO; ARAGÃO, 1996).

Diante disso, o presente artigo tem como objetivo analisar o desenvolvimento de uma Situação de Estudo (SE) para o ensino de Equilíbrio Químico, evidenciando as potencialidades dessa proposta para os processos de ensino e de aprendizagem na Educação Básica.

\section{Metodologia}

O presente trabalho apresenta os resultados de uma atividade de intervenção vivenciado na disciplina de Estágio Supervisionado de regência do curso de Licenciatura em Química de uma Universidade Federal localizada no Estado do Paraná.

O estágio foi realizado em um colégio estadual, em uma turma do $2^{\circ}$ ano do Ensino Médio, contando com a participação de aproximadamente 30 alunos e, por orientação do professor da universidade, deveria contemplar uma abordagem histórica dos conceitos. A partir do conteúdo disponibilizado pelo professor da Educação Básica Equilíbrio Químico - a SE ${ }^{6}$ foi desenvolvida em cinco aulas.

Porém, a fim de auxiliar na elaboração da SE, foi realizado um levantamento prévio acerca das propostas de ensino sobre Equilíbrio Químico em periódicos do Ensino de Ciências, indexados no Qualis/CAPES, na área de Ensino, e avaliados em estratos A1, A2 e B1. Os artigos encontram-se listados no Quadro 1.

\footnotetext{
${ }^{6}$ Para a utilização dessa proposta como dinâmica organizadora das atividades desenvolvidas nesta pesquisa, foram realizadas algumas adaptações na proposta original, visto que, inicialmente, a SE é pensada enquanto uma ferramenta para organização curricular, compreendendo práticas interdisciplinares. Porém, assim como nos trabalhos desenvolvidos por Stanzani et al. (2016) e Massena (2015), as SE serão utilizadas em nosso contexto de forma disciplinar, ou seja, dentro de uma mesma disciplina, entretanto serão "elaboradas buscando-se dar a elas um formato diferenciado do que se vê normalmente em uma aula expositiva" (MASSENA, 2015, p. 48).
} 
DOI: http://dx.doi.org/10.33238/ReBECEM.2020.v.4.n.1.23721

Quadro 1: Artigos que apresentam propostas de ensino sobre Equilíbrio Químico.

\begin{tabular}{|c|c|c|c|}
\hline Código* & Título do artigo/Ano de publicação & Periódico & Qualis \\
\hline Exp01 & $\begin{array}{l}\text { Galinho do Tempo: um jogo didático } \\
\text { para auxiliar o ensino e aprendizagem do } \\
\text { conteúdo equilíbrio químico no ensino } \\
\text { médio/2015 }\end{array}$ & $\begin{array}{c}\text { Experiências em Ensino de } \\
\text { Ciências }\end{array}$ & B1 \\
\hline QNEsc01 & $\begin{array}{l}\text { Equilíbrio Químico de sais pouco } \\
\text { solúveis e o caso Celobar@/2006 }\end{array}$ & Química Nova na Escola & B1 \\
\hline QNEsc02 & $\begin{array}{l}\text { Proposta de um jogo didático para } \\
\text { Ensino do conceito de Equilíbrio } \\
\text { químico/2003 }\end{array}$ & Química Nova na Escola & B1 \\
\hline QNEsc03 & Soprando na água de cal/1999 & Química Nova na Escola & B1 \\
\hline QNEsc04 & \begin{tabular}{llll} 
Algumas & \multicolumn{2}{c}{ experiências } & \multicolumn{2}{c}{ simples } \\
envolvendo o & Princípio & de & Le \\
Chatelier/1997 & & &
\end{tabular} & Química Nova na Escola & B1 \\
\hline
\end{tabular}

* Os códigos são compostos por letras que fazem referência ao título das revistas (p. ex.: Exp - Experiências em Ensino de Ciências) seguido do número indicando a quantidade de artigos encontrados em cada periódico (organizados em relação ao ano de publicação).

Fonte: Os autores (2019)

Analisando o Quadro 1 é possível observar que são poucos os artigos que trazem propostas para que o professor trabalhe o conteúdo de Equilíbrio Químico em sala de aula ${ }^{7}$. Dois artigos, Exp01 e QNEsc02, abordam a utilização de jogos como alternativas pedagógicas para o ensino do conteúdo em questão. O artigo Exp01 descreve o processo de criação e desenvolvimento do jogo intitulado 'O galinho do tempo' em uma turma do $2^{\circ}$ ano do Ensino Médio (PARUSSOLO; LOMBARDE; BARON, 2015). Já o artigo QNEsc02 apresenta uma proposta de jogo didático elaborado a partir de materiais de baixo custo, a qual possibilita a construção de analogias sobre o conteúdo em foco (SOARES; OKUMURA; CAVALHEIRO, 2003). Ambos os artigos destacam as potencialidades das atividades lúdicas para a aprendizagem dos estudantes.

Os outros três artigos listados no Quadro 1 trazem propostas de atividades experimentais que podem auxiliar na construção dos conceitos relacionados ao conteúdo de Equilíbrio Químico.

O artigo QNEsc01 discute a relação entre a solubilidade do carbonato de bário e sua constante de solubilidade por meio de um experimento para demonstrar como íons bário em solução migram para a corrente sanguínea, causando a intoxicação, pelo uso indevido de sais de bário em exames de contraste (SENE et al., 2006).

O artigo QNEsc03 aborda um experimento de demonstração sobre equilíbrio heterogêneo, a partir da reação de dióxido de carbono com a água de cal e sugere

\footnotetext{
7 Dada a extensão do conteúdo 'Equilíbrio Químico', entendemos que nem todos os artigos apresentam propostas dentro do recorte estipulado pelo professor da Educação Básica - reações em equilíbrio e o princípio de Le Chatelier - entretanto, foram consultados a fim de orientar possíveis práticas no contexto da SE desenvolvida.
} 


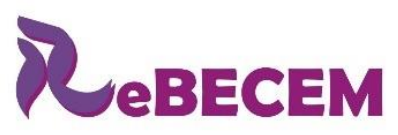

Revista Brasileira de Educação em

Ciências e Educação Matemática

DOI: http://dx.doi.org/10.33238/ReBECEM.2020.v.4.n.1.23721

discussões para seu desenvolvimento em sala de aula (SILVA; STRADIOTTO, 1999).

Por fim, o artigo QNEsc04 traz quatro experimentos utilizando materiais e reagentes de baixo custo, destinados à discussão dos fatores que perturbam o equilíbrio das reações químicas - temperatura, pressão e concentração (FERREIRA; HARTWIG; ROCHAFILHO, 1997).

Mediante esse levantamento inicial, procuramos elaborar uma SE que contemplasse uma gama variada de atividades, como a utilização da História da Ciência, textos e práticas experimentais, a fim de promover um ambiente dinâmico de aprendizagem, no qual os estudantes assumissem um papel ativo na reelaboração dos conceitos. A seguir apresentamos as atividades realizadas em cada aula da SE, intitulada: 'O Galo Mágico'.

\subsection{Aula 1}

Para esta primeira etapa, com o intuito de levantar o conhecimento prévio dos estudantes, utilizamos um problema em que uma garota, ao passar as férias na casa de sua avó, Dona Gertrudes, notou um pequeno galo que enfeitava a casa e tinha sua coloração alterada em dias chuvosos. Curiosa com essa ocorrência, a garota perguntou se a avó havia trocado o galinho por outro de outra cor, e ela respondeu que não.

A partir dessa situação, os alunos, divididos em grupos, deveriam responder à Questão 1: Se Dona Gertrudes não trocou o galinho, como ele pode ter mudado de cor?

Dando continuidade ao problema, a avó explicou que o galinho, presente na família há muito tempo, possuía propriedades mágicas e podia prever o dia em que iria chover. Isso deixou a garota intrigada e com mais dúvidas acerca desse simples adorno. Assim, o problema terminou com a Questão 2: Como a chuva pode ter causado a mudança de cor do galinho?

Na sequência, na segunda etapa - Primeira Elaboração - foram propostos dois experimentos, ambos relacionados a reações reversíveis e irreversíveis, a fim de introduzir o conceito equilíbrio químico em um momento posterior. O primeiro experimento, intitulado 'Água Furiosa', consistiu em uma mistura de glicose, hidróxido de sódio e indicador de azul de metileno. Quando agitada, a solução passa de incolor para azul e, quando deixada em repouso, após alguns instantes, volta a ser incolor, indicando uma reação reversível (BUFFOLO et al., 2016). 
DOI: http://dx.doi.org/10.33238/ReBECEM.2020.v.4.n.1.23721

O experimento 2, exemplo de uma reação irreversível, envolveu a oxidação da palha de aço em contato com a solução de sulfato de cobre. Quando adicionada à solução, a palha de aço, que é composta por ferro metálico, reage com os íons $\mathrm{Cu}^{2+}$, sofrendo oxidação e passando, então, para a forma iônica $\mathrm{Fe}^{2+}$. Consequentemente, os íons $\mathrm{Cu}^{2+}$ sofrem redução, depositando-se sobre a superfície da palha de aço na forma de cobre metálico.

Realizados os experimentos, os grupos foram orientados a responder à Questão 3: Explique, com suas palavras ou por meio de desenhos, os fenômenos observados nas reações envolvidas nos experimentos 1 e 2.

\subsection{Aula 2}

Nesta aula, os alunos realizaram experimentos relacionados ao princípio de Le Chatelier (descritos no Quadro 2), envolvendo os conceitos de temperatura, pressão e concentração.

Quadro 2: Descrição dos experimentos relacionados ao princípio de Le Chatelier

\begin{tabular}{|c|c|}
\hline Experimentos & Descrição \\
\hline 1. Temperatura & $\begin{array}{l}\text { Para a realização deste experimento, foram utilizados três tubos de ensaio contendo } \\
\text { os gases } \mathrm{NO}_{2}(\mathrm{~g}) \text { e } \mathrm{N}_{2} \mathrm{O}_{4(\mathrm{~g})} \text {. Em temperatura ambiente os gases presentes no tubo } \\
\text { apresentavam uma coloração marrom. Na sequência, um dos tubos foi imerso em um } \\
\text { banho de gelo, resultando na diminuição da intensidade da coloração. O segundo } \\
\text { tubo foi submetido ao aquecimento em banho maria, atingindo uma coloração mais } \\
\text { intensa, marrom acastanhada. O terceiro tubo foi utilizado apenas como padrão, a } \\
\text { fim de possibilitar a comparação com o estado inicial. }\end{array}$ \\
\hline 2. Pressão & $\begin{array}{l}\text { Foi utilizada uma seringa contendo água com gás e o indicador ácido vermelho de } \\
\text { metila. Ao puxar o êmbolo da seringa, diminui-se sua pressão interna e } \\
\text { consequentemente o } \mathrm{CO}_{2(\mathrm{~g})} \text { presente na água foi extraído, resultando na diminuição } \\
\text { da acidez da solução, detectada pela coloração propiciada pelo uso do indicador, } \\
\text { tornando-se mais clara se comparada com a coloração inicial. }\end{array}$ \\
\hline 3. Concentração & $\begin{array}{l}\text { Inicialmente preparou-se uma solução saturada de cal virgem e retirou-se o } \\
\text { sobrenadante, no qual se adicionou } \mathrm{CO}_{2(\mathrm{~g})} \text { com auxílio de um canudo, resultando na } \\
\text { formação de um precipitado branco, o carbonato de cálcio. Continuando a adição de } \\
\mathrm{CO}_{2(\mathrm{~g})} \text { ocorreu a dissolução do carbonato de cálcio devido à formação do íon } \\
\text { bicarbonato. }\end{array}$ \\
\hline
\end{tabular}

Fonte: Os autores (2019)

Para cada um dos experimentos foi realizada a questão 4: Qual é a explicação para os fenômenos observados nos experimentos? Na sequência, os estudantes deveriam expor suas respostas, para que os conceitos fossem construídos de maneira coletiva e dialógica.

\subsection{Aula 3}


DOI: http://dx.doi.org/10.33238/ReBECEM.2020.v.4.n.1.23721

Na aula 3 iniciou-se a terceira e última etapa da SE - Função da Elaboração e Compreensão Conceitual, em que os conceitos foram sistematizados a partir das problemáticas e situações propostas ao longo das aulas anteriores. Dessa forma, os futuros professores explicaram sobre conceitos importantes para o entendimento do conteúdo Equilíbrio Químico: reações químicas irreversíveis; constantes de equilíbrio, Kc e Kp; e fatores que afetam o estado de equilíbrio das reações (princípio de Le Chatelier). A parte matemática relacionada ao conteúdo (cálculo das constantes de equilíbrio; gráficos) seria trabalhada em um momento posterior pelo professor da Educação Básica.

\subsection{Aula 4}

Na quarta aula, finalizou-se a sistematização dos conceitos (iniciado na Aula 3) e discutiu-se o contexto histórico do conceito de Equilíbrio Químico, por meio de um texto que discorria sobre a extração do amoníaco, expondo os motivos da pesquisa de Fritz Haber em um período no qual a Alemanha passava por um bloqueio naval e o nitrogênio era de extrema importância para a fabricação de fertilizantes utilizados na agricultura (CANZIAN, 2011; COUTEUR; BURRESON, 2006).

Além disso, o texto abordava a pesquisa de Haber na busca por uma nova maneira de obtenção do nitrogênio, pois as fontes naturais estariam prestes a se esgotar. O recorte histórico ainda citava o sucesso de Haber em seus estudos, sendo laureado com o prêmio Nobel, e trazia também uma discussão dos aspectos contraditórios envolvidos, uma vez que Haber teve participação direta na primeira guerra mundial.

Após a leitura do texto foi proposto aos alunos a Questão 5: O texto aponta que o $N_{2(g)}$ é praticamente um gás inerte, ou seja, pouco reativo. Com base no princípio de Le Chatelier, como você poderia tornar o processo de obtenção de amoníaco favorável?

\subsection{Aula 5}

Como atividade final, foram apresentados alguns exercícios para a generalização do conhecimento e, na sequência, foi realizada uma breve discussão acerca de um novo problema, envolvendo os conceitos estudados na SE.

A problemática contava a história de um garoto chamado Guilherme, que apresenta ao seu professor de Química um problema que estava enfrentando na região em que morava. Ele acusava uma empresa de fertilizantes de ser responsável por uma série 


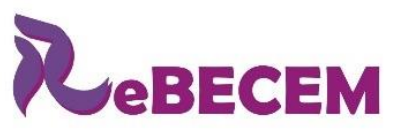

Revista Brasileira de Educação em

Ciências e Educação Matemática

DOI: http://dx.doi.org/10.33238/ReBECEM.2020.v.4.n.1.23721

de problemas de saúde que estavam atingindo os moradores do seu bairro, e seu professor, curioso com o caso, propõe que o garoto investigue e tente encontrar pistas que comprovem suas suspeitas sobre a empresa. Nesse momento, o texto traz a seguinte questão aos alunos (Questão 6): Colocando-se no lugar do Guilherme, o que você iria investigar?

Após uma semana, o garoto apresentou a seu professor uma foto que deixou ambos intrigados, pois se notava que a chaminé da empresa emitia uma fumaça marrom. O professor, sabendo que se tratava de uma empresa de fertilizantes, levantou a hipótese de o gás emitido ser o dióxido de nitrogênio $\left(\mathrm{NO}_{2(\mathrm{~g})}\right)$.

A partir dessa suspeita, Guilherme conseguiu mobilizar a comunidade, exigindo que fossem tomadas providências legais. Após um processo de análise por uma companhia especializada, comprovou-se a emissão do gás referido pelo professor, então a empresa foi notificada e suas atividades foram interrompidas até que o problema fosse solucionado.

Diante disso, o proprietário da empresa de fertilizantes contratou um profissional que lhe garantiu resolver o problema de maneira bem simples e com custo baixo. $\mathrm{O}$ técnico propôs a criação de uma chaminé em forma de serpentina com sistema de resfriamento à base de água. Porém, mesmo após a implementação desse projeto na indústria, e apesar de a fumaça ter sua coloração alterada, os maus sintomas ainda perduravam.

Assim, os alunos deveriam responder à Questão 7: Como você explica essa mudança na cor da fumaça? E por que os sintomas continuaram?

A partir do problema apresentado na extrapolação, abriu-se uma discussão para que os alunos conseguissem resolvê-lo por meio de debates e utilizando todo o material disposto durante as aulas da SE.

No quadro a seguir (Quadro 3), apresentamos um resumo das atividades desenvolvidas nas cinco aulas que integraram a SE aqui relatada e seus respectivos objetivos.

Quadro 3: Resumo das atividades desenvolvidas ao longo da SE - O Galo Mágico

\begin{tabular}{|c|l|l|}
\hline Aulas & \multicolumn{1}{|c|}{ Conteúdo } & \multicolumn{1}{|c|}{ Objetivos } \\
\hline \multirow{3}{*}{01} & $\begin{array}{l}\text { (1) Proposição do problema [1 } \\
\text { etapa da SE]. } \\
\text { (2) Realização de experimentos [ } \mathbf{2}^{\mathbf{a}} \\
\text { etapa da SE]. }\end{array}$ & $\begin{array}{l}\text { (1) Levantar e problematizar as ideias iniciais dos } \\
\text { estudantes acerca de conceitos importantes para o } \\
\text { estudo do conteúdo de Equilíbrio Químico. } \\
\text { (2) Discutir e diferenciar reações reversíveis e } \\
\text { irreversíveis, a fim de introduzir o estudo aos }\end{array}$ \\
\hline
\end{tabular}


DOI: http://dx.doi.org/10.33238/ReBECEM.2020.v.4.n.1.23721

\begin{tabular}{|c|c|c|}
\hline & & $\begin{array}{l}\text { conceitos relacionados ao conteúdo Equilíbrio } \\
\text { Químico. }\end{array}$ \\
\hline 02 & $\begin{array}{l}\text { (1) Realização de experimentos } \\
\text { relacionados ao Princípio de Le } \\
\text { Chatelier. }\end{array}$ & $\begin{array}{l}\text { (1) Construir explicações acerca dos fenômenos } \\
\text { observados nos experimentos, a fim de aprofundar } \\
\text { as discussões teóricas e confrontá-las com as } \\
\text { explicações conceituais apresentadas na terceira } \\
\text { etapa da SE. }\end{array}$ \\
\hline 03 e 04 & $\begin{array}{l}\text { (1) Sistematização dos Conceitos [ } \mathbf{3}^{\mathbf{a}} \\
\text { etapa da } \mathbf{S E}] \text { : as reações reversíveis } \\
\text { e o conceito de equilíbrio químico; } \\
\text { constantes de equilíbrio; princípio } \\
\text { de Le Chatelier. }\end{array}$ & $\begin{array}{l}\text { (1) Apresentar e ressignificar os conceitos de } \\
\text { equilíbrio químico e os fatores que afetam o estado } \\
\text { de equilíbrio (aula expositiva dialogada), sempre } \\
\text { buscando articular as discussões às atividades } \\
\text { realizadas nas etapas anteriores. }\end{array}$ \\
\hline 04 & (1) Abordagem histórica. & $\begin{array}{l}\text { (1) Realizar a discussão de aspectos históricos } \\
\text { relacionados ao desenvolvimento da teoria sobre } \\
\text { Equilíbrio Químico, trazendo um novo problema a } \\
\text { ser resolvido a partir da aplicação dos conceitos } \\
\text { estudados. }\end{array}$ \\
\hline 05 & $\begin{array}{l}\text { (1) Resolução de exercícios e } \\
\text { Extrapolação - Proposição de um } \\
\text { novo problema. }\end{array}$ & $\begin{array}{l}\text { (1) Promover a possibilidade de generalização } \\
\text { conceitual a partir da resolução de novos problemas } \\
\text { relacionados aos conceitos estudados ao longo da } \\
\text { SE. }\end{array}$ \\
\hline
\end{tabular}

Fonte: Os autores (2019)

\subsection{Metodologia de Coleta e Análise dos Dados}

A análise dos resultados ocorreu a partir da coleta de dados realizada mediante as respostas obtidas para cada uma das perguntas e as discussões levantadas em sala de aula, realizadas de forma oral ou escrita.

Os resultados foram organizados e analisados a partir dos pressupostos da Análise de Conteúdo, uma metodologia de pesquisa que, de acordo com Moraes (1999), conduz "[...] a descrições sistemáticas, qualitativas ou quantitativas, ajuda a reinterpretar as mensagens e a atingir uma compreensão de seus significados num nível que vai além de uma leitura comum" (p. 9).

O fundamento da Análise de Conteúdo reside, segundo Bardin (2011, p. 36), "na articulação entre a superfície do texto, descrita e analisada; e os fatores que determinam estas características, deduzidos logicamente", possibilitando ao pesquisador “compreender o sentido da comunicação, mas também e principalmente desviar o olhar para uma outra significação, uma outra mensagem entrevista através ou ao lado da mensagem primeira".

Assim, inicialmente fez-se uma leitura flutuante dos dados coletados em todas as etapas da pesquisa e, a partir disso, estruturaram-se as Unidades de Análise (UA), “[...] processo pelo qual os dados brutos são transformados sistematicamente e agregados em unidades, as quais permitem uma descrição exata das características pertinentes ao 
DOI: http://dx.doi.org/10.33238/ReBECEM.2020.v.4.n.1.23721

conteúdo" (BARDIN, 2011, p. 97). Posteriormente, iniciou-se o movimento interpretativo, visando atingir uma compreensão mais aprofundada do conteúdo analisado, o qual será apresentado a seguir.

\section{Resultados e Discussão}

Com o intuito de organizar melhor a análise dos dados, as discussões foram realizadas a partir das respostas dos estudantes frente às questões levantadas ao longo da SE.

Para a Questão 1 - Se Dona Gertrudes não trocou o galinho, como ele pode ter mudado de cor? - proposta durante a leitura do problema inicial, obtivemos as seguintes respostas (Quadro 4):

Quadro 4: Respostas dos alunos para a questão 1

\begin{tabular}{|c|c|l|}
\hline $\begin{array}{c}\text { Unidades de } \\
\text { Análise }\end{array}$ & Grupos $^{\mathbf{8}}$ & \multicolumn{1}{c|}{ Respostas } \\
\hline Temperatura & G4 & G4: Muda de cor conforme a temperatura do ambiente. \\
\hline Umidade & G2; G3 & $\begin{array}{l}\text { G2: Por causa da umidade do tempo. } \\
\text { G3: Quando o galo teve contato com a água houve uma reação química } \\
\text { que o fez mudar de cor. }\end{array}$ \\
\hline Luminosidade & G3 & G3: Pode ter alguma relação com a luz. \\
\hline Clima & G1; G3 & $\begin{array}{l}\text { G1: Pode ser por causa do clima que alterou a cor do galinho. } \\
\text { G3: Algo relacionado com o dia estar ensolarado e depois chuvoso. }\end{array}$ \\
\hline Outros & $\begin{array}{c}\text { G1; G2; } \\
\text { G3 }\end{array}$ & $\begin{array}{l}\text { G2: [...] pintaram o galo. } \\
\text { G3: A menina era daltônica. }\end{array}$ \\
\hline
\end{tabular}

Fonte: Os autores (2019)

Até esse momento, o problema levantado aos estudantes apresentava apenas a informação de que, quando a garota reparou na mudança de coloração do galinho, o dia estava chuvoso. Como podemos evidenciar nos fragmentos listados no Quadro 4, alguns grupos levantaram a hipótese do contato com a água ou da mudança do clima como a possível causa da alteração descrita pela garota. Outro ponto importante refere-se ao grande número de elementos expostos pelo G3 para justificar o fenômeno em discussão, trazendo inclusive o conceito de reação química.

Todavia apesar de apresentarem ideias relevantes para a solução do problema, os estudantes ainda não foram capazes de estabelecer uma relação entre as hipóteses levantadas e o conceito de Equilíbrio Químico.

\footnotetext{
${ }^{8}$ A fim de manter o anonimato dos estudantes, os grupos foram codificados de G1 a G4, classificados aleatoriamente durante o processo de organização dos dados coletados. O mesmo vale para os estudantes citados nas discussões posteriores (E1, E2 ...). Os dados foram transcritos sem alterações e/ou correções.
} 
DOI: http://dx.doi.org/10.33238/ReBECEM.2020.v.4.n.1.23721

Ainda problematizando as ideias iniciais, a partir do texto, a avó afirmou que o galinho prevê se haverá chuva ou não, porém apresentou a justificativa do bibelô ser mágico. Nesse sentido, os estudantes foram questionados sobre como seria possível esse objeto indicar se a chuva ocorreria ou não. O Quadro 5 traz a categorização das respostas para a Questão 2: Como a chuva pode ter causado a mudança de cor do galinho?

Quadro 5: Respostas dos alunos para a Questão 2

\begin{tabular}{|c|c|l|}
\hline $\begin{array}{c}\text { Unidades de } \\
\text { Análise }\end{array}$ & Grupos & \multicolumn{1}{c|}{ Respostas } \\
\hline Temperatura & G4 & G4: [..] temperatura. \\
\hline Umidade & $\begin{array}{c}\text { G1; G2; } \\
\text { G3; G4 }\end{array}$ & $\begin{array}{l}\text { G1: Depende da umidade do ar. } \\
\text { G2: [...] quando recebe a umidade da chuva muda de cor. }\end{array}$ \\
\hline Luminosidade & G1; G3 & $\begin{array}{l}\text { G3: O galinho já é fabricado azul, mas dependendo da luminosidade } \\
\text { muda de cor. }\end{array}$ \\
\hline Clima & G1; G2; & G4: Por causa de determinados fatores climáticos. \\
\hline Reação Química & G1; G3 & $\begin{array}{l}\text { G1: [...] porque dentro dele pode ter algum produto que reage. } \\
\text { G3: Alguma substância dentro do galinho que fez ele mudar de cor, } \\
\text { em contato com a água. }\end{array}$ \\
\hline
\end{tabular}

Fonte: Os autores (2019)

A partir do novo elemento adicionado à história - previsão da chuva -, percebeuse que os estudantes passaram a elaborar melhor suas hipóteses, buscando solucionar o problema proposto. Citando novamente o caso do G3 como exemplo, notou-se que os estudantes consideraram menos fatores - luminosidade e reação química - na explicação do fenômeno descrito. O G1, por sua vez, começou a relacionar a mudança de coloração a algum tipo de reação química que ocorreu devido à umidade do ar.

Ainda que nem todos os grupos tenham apresentado argumentos que explicassem cientificamente a Questão 2, observou-se que os estudantes colocaram em evidência suas ideias sobre o problema, demonstrando a necessidade de evolução dessas concepções para a aprendizagem do conceito científico. Nesse contexto, de acordo com Silva, Almeida e Campos (2014), “o problema deve ter sentido de aprendizagem, fazendo com que o estudante busque bons resultados, mesmo que as respostas dadas não sejam as melhores, mas, para isso, é preciso que eles reconheçam que suas representações não são suficientes para resolver o problema" (p. 39).

Considerando que as Questões 1 e 2 foram realizadas durante a etapa da problematização - na qual inicialmente os estudantes discutiram as questões nos grupos menores e, em seguida, com toda a turma -, foi possível analisar que as respostas de determinados grupos podem ter influenciado e/ou convencido outros grupos sobre suas respostas estarem mais coerentes com a resolução do problema proposto. Esse fenômeno revela a importância da discussão na construção dos conceitos, cujo objetivo é 


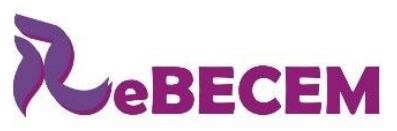

Revista Brasileira de Educação em

Ciências e Educação Matemática

DOI: http://dx.doi.org/10.33238/ReBECEM.2020.v.4.n.1.23721

proporcionar aos estudantes uma participação ativa no processo de ensino e de aprendizagem.

Segundo Coll et al. (2006), é importante permitir que os alunos interajam entre si, pois essas dinâmicas propiciam o surgimento de divergências entre o ponto de vista de cada um, promovendo uma situação problemática, a qual é defendida pelos autores supracitados como o ponto de partida para a aprendizagem.

Acrescenta-se ainda que, nesta etapa, houve uma participação ativa dos alunos, uma vez que questionavam a todo momento os licenciandos para saberem se as respostas estavam corretas ou se as hipóteses levantadas pelos outros grupos seriam coerentes. A problematização motivou a participação e despertou a curiosidade dos alunos, levandoos a comparar o problema em foco em foco a outras situações do seu cotidiano como, por exemplo, a presilha de cabelo que muda de cor em contato com a luz do sol. Essas evidências corroboram o objetivo de motivar o aluno na busca pela construção do conhecimento, elemento importante na primeira etapa da SE (NUÑEZ et al., 2004).

Para a segunda etapa da SE, ainda na primeira aula, os alunos, divididos em quatro grupos, realizaram dois experimentos a fim de exemplificar uma reação reversível e outra irreversível, conforme descrito anteriormente.

$\mathrm{O}$ roteiro apresentava um quadro em que os alunos deveriam anotar suas observações, procurando explicar com as suas palavras ou por meio de desenhos as causas do fenômeno. Assim, apresentamos, no Quadro 6, as respostas dos grupos para a Questão 3: Explique, com suas palavras ou por meio de desenhos, os fenômenos observados nas reações envolvidas nos experimentos 1 e 2.

Quadro 6: Resposta dos grupos referente à questão 3 para o Experimento 1 - Água Furiosa

\begin{tabular}{|c|c|c|}
\hline $\begin{array}{c}\text { Unidades de } \\
\text { Análise }\end{array}$ & Grupos & \multicolumn{1}{c|}{ Respostas } \\
\hline Densidade & G3 & G3: [...] uma possui densidade maior que a outra. \\
\hline $\begin{array}{c}\text { Separação de } \\
\text { Fases }\end{array}$ & G1; G3 & $\begin{array}{l}\text { G1: Primeiro o produto está misturado e estava azul daí ficou em } \\
\text { repouso e o produto desceu para baixo e ficou branco, depois foi } \\
\text { agitado de novo e novamente ficou azul. }\end{array}$ \\
\hline Movimento & G1; G3 & $\begin{array}{l}\text { G3: O metileno entra em contato com a glicose e com a soda e ocorre } \\
\text { uma reação química quando está em movimento. }\end{array}$ \\
\hline Reação Química & G3 & G3: É uma reação reversível. \\
\hline Não responderam & G2; G4 & \\
\hline
\end{tabular}

Fonte: Os autores (2019)

A atividade prática referida anteriormente foi realizada de maneira demonstrativa por dois grupos G1 e G3, a partir de um sorteio prévio. Como os demais apenas 
DOI: http://dx.doi.org/10.33238/ReBECEM.2020.v.4.n.1.23721

observaram e participaram da discussão posterior, acreditamos que julgaram não ser necessário anotar as respostas, justificando a ausência de dados para G2 e G4.

O segundo experimento - oxidação da palha de aço - foi realizado pelos grupos G2 e G4, porém, nesse momento, os estagiários enfatizaram a necessidade de todos os grupos responderem às questões. Ainda assim, o G1 não respondeu os questionamentos, como mostra o Quadro 7.

Quadro 7: Respostas dos alunos referentes à questão 3 (Experimento 2) - Oxidação da Palha de Aço

\begin{tabular}{|c|c|l|}
\hline $\begin{array}{c}\text { Unidades de } \\
\text { Análise }\end{array}$ & Grupos & \multicolumn{1}{c|}{ Respostas } \\
\hline Mudança de cor & G2; G4 & $\begin{array}{l}\text { G2: O sulfato de cobre em contato com o Bombril, faz o Bombril ficar } \\
\text { rosa (muda de cor). }\end{array}$ \\
\hline Dissolução & G3; G4 & G4: [...] a esponja de aço acaba dissolvendo. \\
\hline Catalisador & G2 & $\begin{array}{l}\text { G2: O sulfato de cobre acelera o procedimento no caso de enferrujar } \\
\text { o Bombril ou deixa-lo rosa. }\end{array}$ \\
\hline Reação Química & G3 & $\begin{array}{l}\text { G3: É uma reação irreversível, o Bombril está saindo de sua forma } \\
\text { sólida e entrando em solução. }\end{array}$ \\
\hline Ferrugem & $\begin{array}{c}\text { G2; G3; } \\
\text { G4 }\end{array}$ & $\begin{array}{l}\text { G4: [...] a esponja de aço enferruja ao ter contato com o sulfato de } \\
\text { cobre. }\end{array}$ \\
\hline $\begin{array}{c}\text { Não } \\
\text { responderam }\end{array}$ & G1 & \\
\hline
\end{tabular}

Fonte. Os autores (2019)

Percebe-se que a maioria das respostas dos estudantes limitam-se apenas à descrição das evidências, não estabelecendo relações entre os níveis macro e submicroscópico, a fim de compreender o fenômeno químico envolvido no processo.

Essa dificuldade pode ser verificada mediante a análise dos dados apresentados nos Quadros 6 e 7. Em suas explicações, os estudantes fazem uso de novas palavras/conceitos a fim de descrever os fenômenos observados nos experimentos, porém, as respostas ainda carecem de elaboração conceitual, principalmente no que diz respeito ao nível molecular, uma vez que as ideias de senso comum ainda são muito presentes em suas explicações.

Para o experimento 1, o G1 justifica o fato de a cor da solução alterar entre branca/turva e azul simplesmente pela separação de fases entre os componentes presentes na reação. Já o G3, levanta várias hipóteses para justificar a mudança de cor, citando, inclusive, o conceito de reação reversível, embora não apresente relação entre as hipóteses consideradas. No experimento 2, as hipóteses de formação de ferrugem e de dissolução da palha de aço estão presentes em todas as respostas elaboradas pelos grupos, porém os estudantes apresentam dificuldades na explicação dos fenômenos submicroscópicos. Novamente, o G3 traz o conceito de reação irreversível, mas não apresenta argumentos que justifiquem a hipótese. 


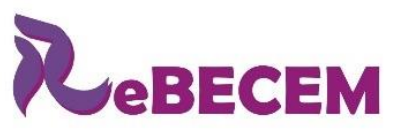

Revista Brasileira de Educação em

Ciências e Educação Matemática

DOI: http://dx.doi.org/10.33238/ReBECEM.2020.v.4.n.1.23721

A figura 1 traz a representação construída pelos estudantes do G3, relacionada à seguinte descrição: O Bombril está saindo de sua forma sólida e entrando em solução.

Figura 1: Representação proposta pelo G3 para o experimento 2

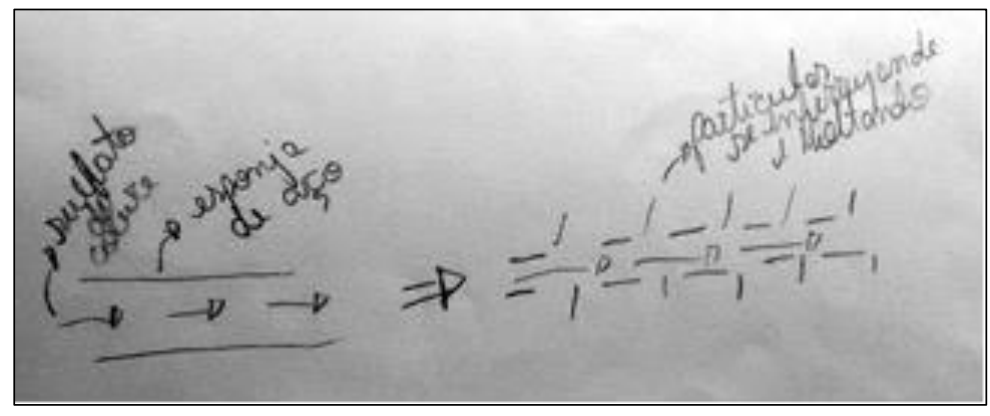

Fonte: Os autores (2019)

No desenho, a esponja de aço é representada por uma barra "sólida e lisa", como uma barra de metal, e a solução de sulfato de cobre interage com a barra e modifica sua estrutura, o que consequentemente faz com que a barra se quebre por meio do processo de formação de ferrugem.

Tais representações corroboram as discussões realizadas por Wartha e Rezende (2011) e Gatto, Gregório e Stanzani (2019). Segundo os autores, é comum os estudantes explicarem os fenômenos químicos utilizando elementos do nível macroscópico, "pois dificilmente possuem competências ou recursos simbólicos, no plano mental, para compreensão das transformações químicas num nível que requer uma maior capacidade de abstração como é o caso do nível submicroscópico" (WARTHA; REZENDE, 2011, p. 278).

O intuito dos experimentos 1 e 2 era fazer com que os estudantes comparassem e pudessem identificar a diferença entre as reações reversíveis e irreversíveis, introduzindo, assim, o conceito de Equilíbrio Químico, porém apenas um dos grupos apresentou essa relação em suas respostas. É importante salientar que os alunos estavam participando de uma atividade experimental pela primeira vez, o que pode ter dificultado o alcance do objetivo proposto nessa aula.

Ainda na segunda etapa da SE, iniciando a segunda aula, os alunos realizaram atividades experimentais relacionadas ao princípio de Le Chatelier, envolvendo os conceitos de pressão, temperatura e concentração (Experimentos 3, 4 e 5).

Após a realização de cada experimento, foi feita uma discussão sobre os resultados observados. Assim, as respostas de cada grupo para as questões referentes aos 
DOI: http://dx.doi.org/10.33238/ReBECEM.2020.v.4.n.1.23721

experimentos - Qual é a explicação para o fenômeno observado nos experimentos? estão elencadas a seguir (Quadro 8).

Quadro 8: Respostas dos alunos referentes à Questão 4 para os experimentos 3, 4 e 5

\begin{tabular}{|c|c|}
\hline Experimento & Observações \\
\hline $\begin{array}{c}\text { Exp. } 3 \text { - } \\
\text { Temperatura }\end{array}$ & $\begin{array}{l}\text { G2: Quando o gás fica na água fria ele fica mais claro, e na quente, marrom. } \\
\text { G4: Na água fria o gás ficou mais claro e na água quente escureceu. É a mesma } \\
\text { substância, mas quando ela está submersa a temperaturas diferentes muda de cor. }\end{array}$ \\
\hline Exp. 4 - Pressão & $\begin{array}{l}\text { G1: Cada vez que puxa, o gás sai da água e daí quando abre a seringa o gás é liberado } \\
\text { e cada vez vai liberando mais ácido. } \\
\text { G2: A pressão da seringa diminui e deixa o líquido menos ácido através da saída do } \\
\text { gás } \mathrm{CO}_{2} \text {. } \\
\text { G4: O gás oxigênio está usando o gás da água e o gás sai por causa da pressão. }\end{array}$ \\
\hline $\begin{array}{c}\text { Exp. } 5 \text { - } \\
\text { Concentração }\end{array}$ & $\begin{array}{l}\text { G1: Se acrescentar mais } \mathrm{CO}_{2} \text { a substância ira enfraquecer. } \\
\text { G2: Com a presença do } \mathrm{CO}_{2} \text { a reação da cal com o } \mathrm{CO}_{2} \text { faz ele virar carbonato e } \\
\text { quanto mais assopra o } \mathrm{CO}_{2} \text { vira carbonato de sódio. As reações mantem um } \\
\text { equilíbrio aumentando em quantidades iguais. } \\
\text { G3: Foi colocado gás carbônico e com isso se misturou e o } \mathrm{Ca}(\mathrm{OH})_{2} \text { foi diluído. } \\
\text { G4: Na substância tinha cal e água, e quando assopramos misturamos o gás } \mathrm{CO}_{2} \text {, } \\
\text { formamos uma reação de equilíbrio, ela vai e volta. O pó sobe a superfície e se } \\
\text { mistura a cada assopro. }\end{array}$ \\
\hline
\end{tabular}

Fonte: Os autores (2019)

Analisando as respostas apresentadas no Quadro 8, constata-se que as dificuldades na explicação do fenômeno químico permanecem. Por exemplo, nas justificativas do G1 e G4 para a influência da temperatura, ambos apenas descrevem, com maior ou menor número de detalhes o evento observado.

Apenas os grupos G2 e G4 relacionam os experimentos à ideia de reação reversível, mencionando o conceito de Equilíbrio Químico, porém o fazem apenas na explicação do experimento 5. Destacamos ainda que na resposta dada pelo G2, que remete à ideia de o sistema atingir o equilíbrio quando as quantidades das substâncias forem as mesmas, "percebe-se neste caso a importância dada aos aspectos mais concretos (massa, peso) em relação a aspectos mais abstratos (interação entre as moléculas na formação de diferentes produtos, em diferentes quantidades dependendo das condições submetidas)" (SANTOS; ANDRADE; IZAIAS, 2016, s/p).

Cabe ainda ressaltar que, de maneira geral, os estudantes percebem e exteriorizam a ação dos agentes externos - variação na temperatura e pressão do sistema e alteração na concentração dos reagentes - como fatores responsáveis pelas mudanças observadas, mesmo que ainda não consigam construir argumentos fundamentados, do ponto de vista científico. É importante destacar também, que essa foi a primeira atividade em que a palavra/conceito equilíbrio foi utilizada pelos alunos para explicar o problema proposto, 
DOI: http://dx.doi.org/10.33238/ReBECEM.2020.v.4.n.1.23721

revelando uma evolução da linguagem e da capacidade argumentativa dos estudantes ao longo das atividades propostas na SE.

$\mathrm{Na}$ terceira e última etapa $\mathrm{SE}$, terceira aula, os conceitos começaram a ser sistematizados e definidos. Como os alunos demonstraram muita resistência na compreensão dos conceitos, houve grande dificuldade em discuti-los em sala de aula. Outro entrave encontrado diz respeito à insegurança dos licenciados no desenvolvimento da abordagem proposta para essa etapa da SE.

Na quarta aula, além da finalizar a apresentação do conteúdo, foi proposta a leitura e a discussão de um texto sobre o contexto histórico do conteúdo. A Questão 5 - Com base no princípio de Le Chatelier, como você poderia tornar o processo de obtenção de amoníaco favorável? - referente ao texto foi respondida individualmente, e estas foram algumas das respostas formuladas pelos estudantes:

E7: Uma forma de aumentar a obtenção de $\mathrm{NH}_{3}$ seria comprimindo os gases $\mathrm{N}_{2}$ e $\mathrm{H}_{2}$, aproximando mais os dois e agilizando o processo de obtenção. $\mathrm{O}$ calor também favoreceria pois agitaria as moléculas, ou também fazer o mais básico, que é aumentando os reagentes iniciais (nitrogênio e hidrogênio) sem precisar se importar com a quantidade, que conforme acontece o processo de formação de amoníaco, o mesmo se degrada voltando ao estado inicial, e assim por diante, já que é uma reação reversível.

E13: Aumentar a pressão para juntar o nitrogênio do hidrogênio, isto é, uma reação favorável; Calor agita as moléculas tem mais probabilidade de uma colisão.

E19: Aumentando a pressão, pois aproxima o nitrogênio do hidrogênio; Calor porque agita as moléculas e temos maior colisão; aumentar a concentração de hidrogênio e nitrogênio.

A partir da sistematização dos conceitos e da leitura e discussão do texto histórico, notou-se que os estudantes, ao buscarem responder à Questão 5, tentaram explicar os fenômenos utilizando conceitos relacionados ao nível submicroscópico, citando, por exemplo, o aumento do grau de agitação das moléculas devido ao aumento da temperatura do sistema e a maior probabilidade de colisão entre as moléculas atrelada ao aumento da pressão como fatores que tornariam a reação de obtenção do amoníaco favorável.

De modo geral, constatamos que os estudantes conseguiram relacionar de forma satisfatória o princípio de Le Chatelier com o processo de Haber Bosch. Porém, ainda existe a dificuldade, assim como nos problemas anteriores, de relacionar os fatores entre si, ou seja, de considerar a relação de dependência entre os fatores, a fim de que a reação se processe e da qual se obtenha um rendimento satisfatório.

Ainda com relação à abordagem histórica, concordamos com Auth et al. (2004) quando afirmam que na SE "não é aceita a ideia de Ciência cristalizada, imutável e 
DOI: http://dx.doi.org/10.33238/ReBECEM.2020.v.4.n.1.23721

produtora de verdades às quais não cabem questionamentos [...] pois quem produz Ciência dificilmente admite verdades definitivas" (p. 255). Enfatiza-se, assim, a importância de contemplar aspectos históricos nos processos de ensino e de aprendizagem das Ciências, evitando-se a propagação de "visões vinculadas ao processo de produção do conhecimento científico que sejam, por exemplo: empírico-indutivista e ateórica, rígida/acabada, a-problemática, a-histórica, exclusivamente analítica, individualista, descontextualizada e socialmente neutra" (SANGIOGO et al., 2013, p. 51).

Portanto, corroborando os argumentos expostos anteriormente, utilizar o contexto histórico durante o desenvolvimento da SE foi essencial para um maior desenvolvimento crítico dos alunos, além de mostrar-lhes que o conhecimento científico não surgiu repentinamente, mas acontece/aconteceu a partir de uma necessidade, incentivando investigações, conflitos de ideias e colaborações entre diversos pesquisadores inseridos em uma comunidade científica. Assim, de acordo com Machado (2014, p. 2), “o estudo da História da Química pode proporcionar aos discentes uma visão mais completa e interligada do desenvolvimento contextualizado dessa Ciência, ou seja, deixando de se tornar algo abstrato para fortalecer um ponto de vista mais crítico e real dos fatos".

Na quinta e última aula da SE, foi proposta uma lista de exercícios abordando os conceitos trabalhados. Os alunos apresentaram muitas dúvidas na resolução das atividades, sendo necessária a intervenção dos futuros professores para explicar e auxiliar os estudantes.

Finalizando a SE, foi indicado outro problema a fim de extrapolar o contexto inicial, desenvolvido em forma de debate. Para as Questões 6 e 7, obtivemos respostas cujos fragmentos mais representativos são apresentados a seguir:

\footnotetext{
Questão 6. Colocando-se no lugar do Guilherme, o que você iria investigar? Respostas: Substância química que faça mal à saúde; radiação; vazamento de gás ou líquido; despejo; descarte; substância química que agride o meio ambiente.

Questão 7. Como você explica essa mudança na cor da fumaça? E por que os sintomas continuaram?

Respostas: Ele só mudou a cor; só mudou de cor; as pessoas só não estão vendo mais, mas ele volta; ele inverte o equilíbrio, volta; só ajudou a empresa; o aumento da temperatura faz o gás voltar.
}

Dessa forma, pode-se observar que os alunos foram capazes de relacionar os conceitos discutidos nas etapas anteriores ao buscarem solucionar o problema vivenciado pelo personagem Guilherme. Nesse contexto, destacamos principalmente a realização dos experimentos envolvendo o princípio de Le Chatelier e do texto histórico, fundamentais 
DOI: http://dx.doi.org/10.33238/ReBECEM.2020.v.4.n.1.23721

na ressignificação das ideias iniciais apresentadas pelos estudantes na etapa da problematização.

Outro ponto relevante, adotado não só para o desenvolvimento da atividade final, mas também durante toda a SE, refere-se aos momentos em que os estudantes foram ativos nos processos de ensino e de aprendizagem, por meio de uma abordagem dialógica, possibilitando que eles pudessem expor suas concepções e ideias e debatê-las com os grupos.

Por fim, foi possível constatar uma evolução dos alunos na elaboração de suas respostas ao longo do estudo da situação proposta. No início da SE, as respostas eram apenas descritivas, sem uma construção muito elaborada; já na última etapa, os alunos, ao se depararem com um problema mais complexo, trouxeram respostas muito mais substanciais ao discutirem os conceitos estudados em um novo contexto, que abordava, além de questões conceituais, aspectos sociais e ambientais, exigindo dos estudantes uma postura crítica frente ao cenário colocado.

\section{Considerações Finais}

Ao refletirmos sobre o desenvolvimento da SE apresentada neste trabalho, destacamos, principalmente, a grande participação dos alunos e o empenho dedicado por eles na resolução dos problemas e atividades propostas. A troca de ideias, os debates e o envolvimento nas atividades de escrita e leitura foram essenciais tanto para a aprendizagem dos alunos como para os licenciandos, que tiveram a oportunidade de, por meio da prática dos estágios, estabelecer a articulação entre as teorias estudadas na universidade com a prática desenvolvida no ambiente escolar - futuro campo de atuação profissional.

Pensar e desenvolver as aulas de acordo com a estrutura sugerida pelos pesquisadores para a SE, nas três etapas, auxiliou no planejamento e na ação do futuro professor em sala de aula. A proposição de um problema relacionado à vivência dos estudantes ( $1^{\text {a }}$ etapa), as atividades de aprofundamento realizadas a partir da proposição de experimentos ( $2^{\mathrm{a}}$ etapa), a discussão conceitual realizada de maneira dialógica e articulada com as etapas anteriores e, finalmente, a proposição de novos problemas em contextos diferentes do inicial ( $3^{a}$ etapa), auxiliaram no processo de ressignificação dos conceitos - nesse caso específico, relacionados ao conteúdo Equilíbrio Químico - e no desenvolvimento do raciocínio e da linguagem científica. 


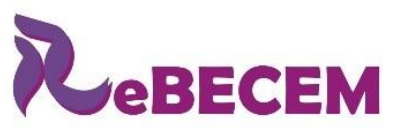

Revista Brasileira de Educação em

Ciências e Educação Matemática

DOI: http://dx.doi.org/10.33238/ReBECEM.2020.v.4.n.1.23721

Destacamos ainda a utilização da abordagem histórica na $3^{\mathrm{a}}$ etapa da SE, que se mostrou extremamente relevante na discussão de novos conceitos e na formação do senso crítico dos estudantes, mostrando que a ciência está em constante evolução e evitando, assim, a propagação de visões distorcidas a seu respeito.

Em relação aos obstáculos enfrentados durante o desenvolvimento das aulas, tivemos algumas dificuldades referentes à própria adequação das atividades dentro das orientações da SE. Citamos como exemplo o retorno ao problema inicial, que, de acordo com os autores, deve acontecer na terceira etapa da SE. Devido à falta de controle de tempo, à inexperiência dos licenciandos na gestão de sala e conteúdo - uma vez que a disciplina de Estágio possibilita o primeiro contato do estudante com a realidade escolar no papel de professores -, o problema do 'Galo do Tempo' não foi retomado ao final da proposta, portanto os estudantes não tiveram a possibilidade de confrontar suas ideias iniciais após as discussões e reflexões conceituais propiciadas no decorrer das aulas.

Por fim, em uma autoavaliação realizada pelos licenciandos responsáveis pela elaboração da SE analisada no presente trabalho, destacam-se as potencialidades da SE como uma dinâmica que, ao colocar o aluno como protagonista do processo de ensino e de aprendizagem, possibilita uma formação mais crítica e cidadã.

\section{Referências}

AUTH, M. A.; MALDANER, O. A.; WUNDER, D. A.; FIUZA, G. S. Situação de estudo na área de ciências do ensino médio: rompendo fronteiras disciplinares. In: MORAES, R.; MANCUSO, R. (org.). Educação em ciências: produção de currículos e formação de professores. Ijuí: Editora Unijuí, 2004. p. 253-276.

BARDIN, L. Análise de Conteúdo. São Paulo: Edições 70, 2011.

BUFFOLO, K. M. et al. Os três aspectos do conhecimento químico interligados em uma sequência didática sobre reversibilidade. In: ENCONTRO NACIONAL DE ENSINO DE QUÍMICa. Florianópolis, 2016. Anais... UFSC: Florianópolis, 2016.

CANZIAN, R. Análise do princípio de Le Chatelier em livros didáticos de química. 2011. Dissertação (Mestrado). Instituto de Química, Instituto de Física, Instituto de Biociências e Faculdade de Educação, Universidade de São Paulo, São Paulo, 2011.

CARVALHO, A. M. P. Ensino de ciências por investigação: condições para implementação em sala de aula. São Paulo: Cengage Learning, 2013.

COLL, C. et al. O construtivismo em sala de aula. São Paulo: Editora Ática. 2006.

COUTEUR, P. L., BURRESON, J. Os Botões de Napoleão: as 17 moléculas que mudaram história. Rio de Janeiro: Zahar, 2006. 
DOI: http://dx.doi.org/10.33238/ReBECEM.2020.v.4.n.1.23721

DELIZOICOV, D.; ANGOTTI, J. A.; PERNAMBUCO, M. M. Ensino de ciências: fundamentos e métodos. 3 ed. São Paulo: Cortez, 2009.

FERREIRA, L. H.; HARTWIG, D. H.; ROCHA FILHO, R. C. Algumas Experiências Simples Envolvendo o Princípio de Le Chatelier. Química Nova na Escola, v. 5, n. 5, p. 28-31, 1997.

GATTO, M. A.; GREGORIO, A. P. H.; STANZANI, E. L. Situação de Estudo no Ensino de Cinética Química: possibilidade a partir de uma abordagem histórica. Experiências em Ensino de Ciências, v. 14, n. 1, p. 160-176, 2019.

GEHLEN, S. T.; MALDANER, O. A.; DELIZOICOV D. Momentos pedagógicos e as etapas da situação de estudo: complementaridades e contribuições para a Educação em Ciências. Ciência \& Educação, Bauru, v. 18, n. 1, 2012.

MACHADO, A. H.; ARAGÃO, R. M. R. Como os estudantes concebem o estado de Equilíbrio Químico. Química Nova na Escola, v. 4, p. 18-20, 1996.

MACHADO, S. F. R. Abordagem da história da química em escolas de ensino médio de Caçapava do Sul/RS. 2014. TCC (Graduação) - Curso de Ciências Exatas, Universidade Federal do Pampa, Caçapava do Sul, 2014.

MALDANER, O. A. Situações de estudo no ensino médio: nova compreensão de educação básica. In: NARDI, R. (org.). Pesquisa em ensino de ciências no Brasil: alguns recortes. São Paulo: Escrituras, 2007, p. 237-253.

MALDANER, O. A. et al. Situação de estudo como possibilidade concreta de ações coletivas interdisciplinares no ensino médio - ar atmosférico. In: ENCONTRO NACIONAL DE PESQUISA EM EDUCAÇÃO EM CIÊNCIAS, 3., 2001, Atibaia, 2001. Anais... ABRAPEC: Atibaia, 2001.

MASSENA, E. P. A formação inicial de professores de química pensada a partir de alguns pressupostos do educar pela pesquisa. Educação Unisinos, v. 19, n. 1, p. 45-56, 2015.

MORAES, R. Análise de Conteúdo. Educação, Porto Alegre, ano XXII, n.37, p. 7-31, 1999.

NUÑEZ, I. B. et al. O uso de situações problema no ensino de ciências. In: NUÑEZ, I. B.; RAMALHO, B. L. (orgs.). Fundamentos do ensino-aprendizagem das ciências naturais e da matemática: o novo ensino médio. Porto Alegre: Sulina, 2004, p. 145-171.

PARUSSOLO, A. P.; LOMBARDE, W.; BARON, A. M. Galinho do Tempo: Um jogo didático para auxiliar o ensino e aprendizagem do conteúdo equilíbrio químico no ensino médio. Experiências em Ensino de Ciências, v. 10, n. 1, p. 141-146, 2015.

SÁ, L. P.; QUEIROZ, S. L. Estudo de casos no ensino de Química. Campinas: Átomo, 2009.

SANGIOGO, F. A. et al. Pressupostos epistemológicos que balizam a Situação de Estudo: algumas implicações ao processo de ensino e à formação docente. Ciência \& Educação, v. 19, n. 1, p. 35-54, 2013.

SANTOS, A. C. O.; ANDRADE, T. S.; IZAIAS, R. D. Concepções de Equilíbrio e Equilíbrio Químico: uma alternativa para a construção do conhecimento científico. In: ENCONTRO NACIONAL DE ENSINO DE QUÍMICA, Florianópolis, 2016. Anais... Florianópolis: UFSC, 2016. 
DOI: http://dx.doi.org/10.33238/ReBECEM.2020.v.4.n.1.23721

SANTOS, W. L. P.; AULER, D. (org). CTS e educação científica: desafios, tendências e resultados de pesquisa. Brasília: Editora UnB, 2013.

SENE, J. J. et al. Equilíbrio Químico de Sais Poucos Solúveis e o Caso Celobar. Química Nova na Escola, n. 24, p. 43-45, 2006.

SILVA, F. C. V.; ALMEIDA, M. A. V.; CAMPOS, A. F. O trabalho com situação-problema utilizando elementos do ensino por pesquisa: análise das impressões de futuros professores de química. REnCiMa, v. 5, n. 1, p. 37-48, 2014.

SILVA, J. L.; STRADIOTTO, N. R. Soprando na Água de Cal. Química Nova na Escola, São Paulo, n. 10, p. 52-53, 1999.

SOARES, M. H. F. B.; OKUMURA, F.; CAVALHEIRO, E. T. G. Proposta de um Jogo Didático para Ensino do Conceito de Equilíbrio Químico. Química Nova na Escola, v. 18, n. 1, p. 13-17, 2003.

STANZANI, E. L. Saberes Docentes e a Prática nos Estágios: possibilidades na formação do futuro professor de Química. 2018. Tese (Doutorado em Educação para a Ciência) - Faculdade de Ciências, Universidade Estadual 'Júlio de Mesquita Filho', Bauru, 2018.

STANZANI, E. L.; GUARNIERI, P. V.; CARVALHO, W.; OBARA, C. E. Situação de Estudo e Ensino de Química: contribuições para a Educação Científica. In: ENCONTRO NACIONAL DE ENSINO DE QUÍMICA, 2016, Florianópolis. Anais... Florianópolis: UFSC, 2016.

WARTHA, E. J.; REZENDE, D. B. Os níveis de representação no ensino de química e as categorias da semiótica de Peirce. Investigações em Ensino de Ciências, Porto Alegre, v. 16, n. 2, p. 275-290, 2011.

Recebido em: 04 de dezembro de 2019

Aceito em: 04 de março de 2020 